\title{
Erosion and deposition in the JET divertor during the second ITER-like wall campaign
}

\author{
M. Mayer ${ }^{\mathrm{a}, \star}$, S. Krat ${ }^{\mathrm{a}, \mathrm{b}}$, A. Baron-Wiechec ${ }^{\mathrm{c}}$, Yu. Gasparyann ${ }^{\mathrm{b}}$, K. Heinola ${ }^{\mathrm{d}}$, \\ S. Koivuranta ${ }^{\mathrm{e}}$, J. Likonen ${ }^{\mathrm{e}}$, C. Ruset ${ }^{f}$, G. de Saint-Aubin ${ }^{\mathrm{a}}$, A. Widdowson ${ }^{\mathrm{c}}$, and JET \\ Contributors $^{1}$
}

\begin{abstract}
EUROfusion Consortium, JET, Culham Science Centre, OX14 3DB, Abingdon, UK
${ }^{a}$ Max-Planck-Institut für Plasmaphysik, Garching, Germany

${ }^{b}$ National Research Nuclear University MEPhI (Moscow Engineering Physics Institute), Moscow,
\end{abstract}

Russia

${ }^{C}$ Culham Centre for Fusion Energy, Culham Science Centre, Abingdon, UK

${ }^{d}$ University of Helsinki, Finland

${ }^{e}$ VTT Technical Research Centre of Finland, Finland

${ }^{f}$ National Institute for Laser, Plasma and Radiation Physics, Bucharest, Romania

\begin{abstract}
*Corresponding author: tel.: +49 89 32991639, e-mail: matej.mayer@ipp.mpg.de (M. Mayer)
${ }^{1}$ See the author list of "Overview of the JET results in support to ITER" by X. Litaudon et al., to be published in Nuclear Fusion Special issue: overview and summary reports from the $26^{\text {th }}$ Fusion Energy Conference (Kyoto, Japan, 17-22 October 2016)
\end{abstract}

Erosion of plasma-facing materials and successive transport and redeposition of eroded material are crucial processes determining the lifetime of plasma-facing components and the trapped tritium inventory in redeposited material layers. Erosion and deposition in the JET divertor were studied during the second JET ITER-like wall campaign ILW-2 in 2013 - 2014 by using a poloidal row of specially prepared divertor marker tiles including the tungsten bulk tile 5 . The marker tiles were analysed using elastic backscattering with 3 to $4.5 \mathrm{MeV}$ incident protons and nuclear reaction analysis using 0.8 to $4.5 \mathrm{MeV}^{3} \mathrm{He}$ ions before and after the campaign.

The erosion/deposition pattern observed during ILW-2 is qualitatively comparable to the first campaign ILW-1 in 2011 - 2012: Deposits consist mainly of beryllium with 520 at.\% of carbon and oxygen and small amounts of $\mathrm{Ni}$ and $\mathrm{W}$. The highest deposition with deposited layer thicknesses up to $30 \mu \mathrm{m}$ per campaign is still observed on the upper and horizontal parts of the inner divertor. Outer divertor tiles $5,6,7$ and 8 are net $W$ erosion areas. The observed $D$ inventory is roughly comparable to the inventory observed during ILW-1. The results obtained during 
ILW-2 therefore confirm the positive results observed in ILW-1 with respect to reduced material deposition and hydrogen isotopes retention in the divertor. 


\section{Introduction}

Erosion of plasma-facing materials due to bombardment by energetic ions from the plasma and the successive transport and redeposition of eroded material [1] are crucial processes determining the lifetime of plasma-facing components in fusion devices. Redeposited layers can contain large amounts of hydrogen isotopes by codeposition and are the determining factor for the total trapped tritium inventory inside a fusion device when using a burning D-T plasma. Erosion/deposition processes inside the JET vessel have been studied experimentally during the transition from all-carbon to a beryllium/tungsten wall in order to obtain experimental data about the global material migration pattern with the different wall configurations. During operation of JET with all-carbon walls prior to the year 2010 (JET-C) large redeposition of carbon with some beryllium and elements from Inconel components $(\mathrm{Ni}, \mathrm{Fe}, \mathrm{Cr})$ was observed in the whole inner divertor, some fraction of the outer divertor, and in remote divertor areas $[2,3,4,5]$. Carbon originated mainly from chemical erosion by hydrogen in the main chamber $[5,6,7]$. This large deposition of carbon was accompanied by a high retention of hydrogen isotopes trapped in the carbon layers by co-deposition.

Due to this observed high retention of hydrogen isotopes with carbon walls ITER will use beryllium as plasma-facing material in the main chamber and tungsten in the divertor [8] for reducing the tritium inventory by at least an order of magnitude below that observed with carbon plasma-facing components (PFCs) [9]. JET with its ITERlike wall (ILW) [10] has been used since the year 2011 to study plasma-wall interaction with this ITER-specific material distribution [11].

During the first operational campaign of JET with the ITER-like wall (ILW-1) in the years 2011-2012 profound changes of the material erosion/deposition pattern in the divertor were observed, as compared to the previous operation of JET with all carbon walls: The total mass of deposited material decreased by a factor of 4-9 [5], and the deuterium retention inside the JET vessel decreased by a factor of 10 to 20 [12]. These results are highly promising for the extrapolated tritium retention in ITER.

However, the ILW-1 campaign was characterised by a relatively small variation of strike point positions (with the inner plasma strike point mostly on the vertical divertor tile 3 and the outer plasma strike point on the bulk $W$ tile 5 , see section 2), and by low heating powers. It is therefore of crucial importance to confirm the obtained 
promising results from ILW-1 also during the second JET campaign with the ITER-like wall (ILW-2) in the years 2013-2014, which had an almost identical length of the campaign but showed a larger variation of strike point positions and somewhat higher heating powers.

\section{Experimental}

The JET divertor as used during both ILW campaigns is shown in Fig. 1. Tiles 1, 3 and 4 form the inner and tiles 5, 6, 7, 8 the outer divertor. All tiles except of tile 5 consist of carbon-fiber composite material coated with about $20 \mu \mathrm{m}$ tungsten [13]; Tile 5 consists of rows of lamellae made from bulk tungsten [14].

During the second JET ITER-like wall campaign 2013 to 2014 (ILW-2) in total 4150 discharges were performed, see Table 1. The integrated discharge time of successful discharges (with a plasma current above $0.7 \mathrm{MA}$ ) was $20300 \mathrm{~s}(5.6 \mathrm{~h}$ ) in limiter configuration and $50900 \mathrm{~s}(14.1 \mathrm{~h})$ in divertor configuration. This is only about $10 \%$ higher than during the first JET ITER-like wall campaign 2011 to 2012 (ILW-1). The total input energy in ILW-2 was 200.5 GJ, which is about $30 \%$ higher than in ILW-1.

Many different types of discharges were performed in ILW-2, the divertor strike point distributions for ILW-1 and ILW-2 are compared in Fig. 2. In ILW-1 the inner strike point was usually on tile 3 and the outer strike was usually on tile 5 , while in ILW-2 the strike points were more often on tiles 4 and 6 .

While ILW-1 was operated only in deuterium, ILW 2 was ended with $0.6 \mathrm{~h}$ of plasma operation in hydrogen.

All poloidal positions on divertor tiles are described using the s-coordinate system commencing in the upper left corner of tile 0 and following the tile surfaces from the inner to the outer divertor, see Fig. 1.

A set of marker tiles (tiles $1,3,6,7,8$ ) was coated with a tungsten marker layer having a thickness of about $3 \mu \mathrm{m}$ with a $3 \mu \mathrm{m}$ thick molybdenum interlayer to the thick tungsten coating for distinguishing the $\mathrm{W}$ marker layer from the $\mathrm{W}$ coating [15]. The tungsten marker allows determining erosion of tungsten as well as the quantitative determination of deposition of all elements. Tile 0 was a regular tile without marker coating: This tile therefore allows only determining deposition. Tile 4 
was without the tungsten marker layer and had the molybdenum layer on top. The marker tiles were installed before ILW-2.

The thicknesses of the marker layers were analysed using non-destructive ion-beam analysis methods before installation inside JET. After exposure samples with a diameter of $18 \mathrm{~mm}$ were cut from the tiles. These samples were analysed using a glove-box due to the toxic beryllium content [16].

Tile 5 consists of bulk tungsten lamellae [14]. Twelve lamellae were coated with about $5 \mu \mathrm{m} \mathrm{Mo} / 5 \mu \mathrm{m} \mathrm{W}$ marker layers and installed before the ILW-2 campaign.

The thicknesses of marker layers and of thick deposits were determined using elastic backscattering (EBS) with $3-4.5 \mathrm{MeV}$ incident protons at a scattering angle of $165^{\circ}$. Nuclear reaction analysis (NRA) with incident ${ }^{3} \mathrm{He}$ ions at energies from 0.8 to $4.5 \mathrm{MeV}$ was applied at a reaction angle of $135^{\circ}$ to measure the amounts of $\mathrm{D}, \mathrm{Be}$ and $C$. The $D$ content was measured using the $D\left({ }^{3} \mathrm{He}, \mathrm{p}\right)^{4} \mathrm{He}$ reaction [17], the ${ }^{9} \mathrm{Be}\left({ }^{3} \mathrm{He}, \mathrm{p}_{0}\right){ }^{11} \mathrm{~B}$ and ${ }^{9} \mathrm{Be}\left({ }^{3} \mathrm{He}, \mathrm{p}_{1}\right){ }^{11} \mathrm{~B}$ reactions were used for measuring the $\mathrm{Be}$ content.The ${ }^{12} \mathrm{C}\left({ }^{3} \mathrm{He}, \mathrm{p}_{0}\right){ }^{14} \mathrm{~N}$ reaction was used to determine the amount of ${ }^{12} \mathrm{C}$. In order to take overlap with protons from the ${ }^{9} \mathrm{Be}\left({ }^{3} \mathrm{He}, \mathrm{p}_{3}\right){ }^{11} \mathrm{~B}$ reaction into account the number of protons from this reaction was simulated using cross-section data from [18] and subtracted from the ${ }^{12} \mathrm{C}\left({ }^{3} \mathrm{He}, \mathrm{p}_{0}\right){ }^{14} \mathrm{~N}$ peak. For very thin layers protons from the ${ }^{12} \mathrm{C}\left({ }^{3} \mathrm{He}, \mathrm{p}_{1}\right){ }^{14} \mathrm{~N}$ reaction were also used to determine the amount of ${ }^{12} \mathrm{C}$, in that case overlap with ${ }^{9} \mathrm{Be}\left({ }^{3} \mathrm{He}, \mathrm{p}_{6}\right){ }^{11} \mathrm{~B}$ and ${ }^{9} \mathrm{Be}\left({ }^{3} \mathrm{He}, \mathrm{p}_{7}\right){ }^{11} \mathrm{~B}$ peaks was checked using cross-section data from [19].

The beam spot size was about $1 \times 1 \mathrm{~mm}^{2}$. Measured EBS and NRA spectra were evaluated using the SIMNRA code [20] with SRIM 2013 stopping power [21], the surface roughness was taken into account in the simulations [ 22 ]. EBS measurements of $\mathrm{W}$ and Mo layer thicknesses are accurate within about $5 \%$ for erosion areas and thin deposits. For thick deposits total amounts of deposited elements can be determined with an accuracy of $10-20 \%$ from the EBS data. The accuracy of the NRA data is about $10 \%$ for D and $20 \%$ to $30 \%$ for Be and C.

\section{Results and discussion}

Thicknesses of the $\mathrm{W}$ and Mo marker layers before and after exposure during the ILW-2 campaign together with the total deposition of Be and $C$ and the $D$ inventory on 
the marker tiles are shown in Fig. 3. The distribution of strike point positions is shown in Fig. 3 (lowest figure).

The thickest deposits are found on tile 0 and the horizontal and sloped parts of tile 1 , see Fig. 1. Deposits consist mainly of beryllium with about $5 \%$ carbon and $1-3 \%$ deuterium. In addition deposits contain some oxygen, which was difficult to quantify. Elements from the Inconel wall ( $\mathrm{Ni}, \mathrm{Fe}$ and $\mathrm{Cr}$ ) as well as tungsten were observed in small quantities. Deposited layers on tiles 0 and 1 are generally rough and often have a stratified structure, see for example [5, Fig. 6].

Depth profiles of deuterium in thick deposited layers on tile 1 are shown in Fig. 4 for two different s-coordinates. The deuterium concentration in the deposited layers is between 1.5 and 3.5 at.\% and relatively homogeneous with depth. It has to be noted, however, that NRA averages over the whole beam spot, i.e. lateral variations of the $D$ concentration on a smaller scale than about $1 \mathrm{~mm}$ cannot be resolved. The $D$ concentration in the $\mathrm{W}$ marker layer is considerably smaller than in the deposited (mainly Be containing) layer. Accumulation of $D$ at the interface between the deposit and the $\mathrm{W}$ marker layer is observed at some places, for example at $\mathrm{s}=266 \mathrm{~mm}$ (see Fig. 4).

Deposits are also observed on the sloping parts of tiles 4 and 6 close to the maxima of the strike point distribution. As already shown in [5, Fig. 4] deposits on tiles 4 and 6 are found predominantly in the valleys of the rough CFC surfaces. Deposits on tile 4 are richer in carbon with $\mathrm{C} / \mathrm{Be}$ of the order of one and contain some deuterium. Very thick codeposited hydrocarbon deposits were observed in these regions with JET-C prior to 2010 [2].

Tile 4 did not have a W marker coating but had Mo at the surface. Some redeposition of $W$ is observed on this tile. $W$ can originate from erosion in the main chamber, where some fraction of the recessed wall has been coated with $W$ and net $W$ erosion has been observed [6], or from erosion in the outer divertor. Some erosion of the Mo coating is observed at the position of the inner strike point on the sloping part of tile 4 at s-coordinates in the range $810-840 \mathrm{~mm}$. The total amounts of $\mathrm{D}, \mathrm{Be}$ and $\mathrm{C}$ deposited in the divertor are summarised in Table 2. More than 2/3 of the detected Be and $D$ are found in deposits on tiles 0 and 1. Within the experimental uncertainties the total amounts are almost identical to the amounts of deposited material during ILW-1, see [5, Table 1]. 
Clear erosion of the $\mathrm{W}$ marker layer is observed in the outer divertor on tiles 5 and 6, small erosion is visible on tiles 7 and 8 , see Fig. 3 . It is noteworthy that the W-erosion on tiles 5 and 6 is almost similar although the strike-point time on tile 6 was considerably larger (see Fig. 3), i.e. the net erosion yield is considerably higher on tile 5 as compared to tile 6 . This can be due to the different surface roughnesses: Tile 5 consists of bulk $\mathrm{W}$ with a relatively smooth surface, while the bulk material of tile 6 is CFC with a much higher surface roughness. It has been already observed at the outer strike point of ASDEX Upgrade that the erosion of $\mathrm{W}$ markers is smaller by a factor of up to 5 on rough surfaces as compared to smooth surfaces [23].

Two modules of the bulk tungsten tile 5 are shown in Fig. 5. Each module consists of 24 rows of bulk tungsten lamellae in toroidal direction arranged in 4 stacks in poloidal direction; see Fig. 1 for a cross-sectional view. Lamellae rows 2, 13 and 22 contained Mo/W markers (marked in yellow in Fig. 5). In addition the neighboring rows 3, 14 and 23 of regular bulk W lamellae were analyzed and are marked in orange in Fig. 5. Neighboring modules shadow each other for edge protection, so that rows 2 and 3 were in the plasma shadow and received smaller power- and particle fluxes than the other analyzed lamellae. The smaller power fluxes resulted also in reduced surface temperatures.

Thicknesses of the $\mathrm{W}$ and Mo marker layers on lamellae of row 2 before and after exposure and the total deposition of $\mathrm{Be}, \mathrm{C}$ and $\mathrm{D}$ on the marker lamellae of row 2 and on regular lamellae of row 3 are shown in Fig. 6 . Both rows of lamellae were in the shadow of the neighboring module, see above. The marker layers delaminated from stack B, so that post-exposure values are not available from that stack. The thicknesses of the $\mathrm{W}$ marker layers are almost identical before and after exposure, i.e. erosion of $\mathrm{W}$ is not detected within the measurement accuracy. Only on stack $\mathrm{D}$ a small erosion of $\mathrm{W}$ is observed. Deposition of $\mathrm{Be}$ and $\mathrm{C}$ is small and stays below $1.5 \times 10^{18}$ atoms $/ \mathrm{cm}^{2}$, the highest deposition is observed on stack $D$. The amount of retained $D$ is also low and stays below $0.3 \times 10^{18}$ atoms $/ \mathrm{cm}^{2}$, the highest retention is observed on stack $D$. In contrast to tiles 4 and 6 , where codeposition of $D$ with $\mathrm{Be}$ and $C$ in the valleys of the rough CFC surface plays a role for D retention [5, Fig. 4], $D$ retention on the smoother bulk $W$ tile 5 is probably dominated by diffusion of $D$ into $\mathrm{W}$ and trapping at lattice defects. This is suggested because the $\mathrm{W}$ marker layer showed a higher $\mathrm{D}$ retention than the regular bulk $\mathrm{W}$, probably due to a higher 
density of lattice defects in the layer due to the deposition process. As deuterium is trapped at defects in W a higher defect concentration also results in higher deuterium retention. This is further confirmed by $D$ depth profiles which show diffusion of $D$ until depths of more than $1 \mu \mathrm{m}$, see below.

Thicknesses of the $\mathrm{W}$ and Mo marker layers on lamellae of row 13 before and after exposure and the total deposition of $\mathrm{Be}, \mathrm{C}$ and $\mathrm{D}$ on the marker lamellae of row 13 and on regular lamellae of row 14 are shown in Fig. 7. Some delamination of the marker layer was observed on stack $D$, so that only limited post-exposure values are available from that stack. Erosion of $W$ is not observed within the measurement accuracy on stacks $A$ and $B$. Erosion of $W$ up to $1 \times 10^{19} \mathrm{~W}$-atoms $/ \mathrm{cm}^{2}$ (about $1.5 \mu \mathrm{m}$ ) is observed on stack $C$. Deposition of $B e$ and $C$ is small and stays below $1.5 \times 10^{18}$ atoms $/ \mathrm{cm}^{2}$, the highest deposition is observed on stack $\mathrm{D}$. Deposition is very low on the other stacks. The amount of retained $D$ is also low and stays below $0.2 \times 10^{18}$ atoms $/ \mathrm{cm}^{2}$. The highest retention is observed on stack $A$ where the strike point has never been located. The lowest retention is observed on stack $C$, probably due to higher surface temperatures. Again, the $\mathrm{W}$ marker layer showed a higher $\mathrm{D}$ retention than the regular bulk $\mathrm{W}$.

Thicknesses of the $\mathrm{W}$ and Mo marker layers on lamellae of row 22 before and after exposure and the total deposition of $\mathrm{Be}, \mathrm{C}$ and $\mathrm{D}$ on the marker lamellae of row 22 and on regular lamellae of row 23 are shown in Fig. 8. Some delamination of the marker layer was observed on stack D, so that only limited post-exposure values are available from that stack. Erosion of $\mathrm{W}$ is not observed within the measurement accuracy on stack $A$. Erosion of $W$ up to $1 \times 10^{19} \mathrm{~W}$-atoms $/ \mathrm{cm}^{2}$ (about $1.5 \mu \mathrm{m}$ ) is observed on stacks $B$ and $C$, with the highest erosion on stack $C$. Deposition of $B e$ and $C$ is small and stays below $1.0 \times 10^{18}$ atoms $/ \mathrm{cm}^{2}$, the highest deposition is observed on stack D. Deposition is very low on the other stacks. The amount of retained $D$ is also low and stays below $0.2 \times 10^{18}$ atoms $/ \mathrm{cm}^{2}$. The highest retention is observed on stack $A$ where the strike point has never been located. The lowest retention is observed on stack $C$, probably due to higher surface temperatures. Again, the $\mathrm{W}$ marker layer showed a higher $\mathrm{D}$ retention than the regular bulk $\mathrm{W}$.

Deuterium depth profiles from stacks $A$ and $C$ in row 14 (regular bulk $W$ ) of tile 5 are shown in Fig. 9 and compared to depth profiles from the ILW-1 campaign at the same position. After ILW-1 the highest deuterium concentrations (up to almost 2 at.\%) were 
observed close to the surface. After ILW-2 the near-surface layers (up to a depth of $0.5-1 \times 10^{18}$ at. $/ \mathrm{cm}^{2}$, about $75-150 \mathrm{~nm}$ ) were depleted of deuterium. This may be due to isotopic exchange with protium during the hydrogen discharges at the end of the ILW-2 campaign. Stack $C$ received higher particle fluxes and the D-depleted zone extends deeper into the bulk $W$. In depths above about $1 \times 10^{18}$ at. $/ \mathrm{cm}^{2}$ (about $150 \mathrm{~nm}$ ) the $\mathrm{D}$ concentrations after ILW-1 and ILW-2 are comparable.

\section{Summary}

During operation of JET with all-carbon walls high erosion and succeeding redeposition of carbon were observed and accompanied by a high retention of hydrogen isotopes trapped in the redeposited carbon layers. Due to this high retention of hydrogen isotopes with carbon walls ITER will use beryllium and tungsten as plasma-facing materials for reducing the tritium inventory. JET with its ITER-like wall (ILW) was used to study plasma-wall interaction with this ITER-specific material distribution and could demonstrate profound changes of the material erosion/deposition pattern during the first operational campaign ILW-1: The total mass of deposited material decreased by a factor of 4-9 and the deuterium retention inside the JET vessel decreased by a factor of 10 to 20 . However, these highly promising results need further confirmation from the second operational campaign ILW-2.

The JET discharge campaigns ILW-2 in 2013 - 2014 and ILW-1 in 2011 - 2012 have some similarities, but show also some differences: Both campaigns have comparable total numbers of discharges and comparable total discharge times. Main differences are a different distribution of strike point positions in ILW-2 with the inner strike point more often on tile 4 and the outer strike point on tile 6; somewhat more powerful discharges in ILW-2; and the completion of ILW-2 with several days of operation in hydrogen.

These similarities and differences in plasma operation are also reflected in the erosion/deposition pattern in the divertor. In both ILW campaigns deposition is mainly observed in the upper inner divertor on tiles 0 and 1. Deposits consist mostly of beryllium with some carbon and oxygen; smaller amounts of tungsten, nickel, iron and chromium are also observed. These deposits contain 1-3 at.\% of deuterium by codeposition. Deposition of Be and $C$ together with codeposition of $D$ is observed on 
tiles 4 and 6 in both campaigns, but is more pronounced in ILW-2 due to the different strike point distribution with the strike points more often on these tiles. Deposits on tile 4 are richer in carbon.

Tungsten erosion is observed in the outer divertor on tiles 5, parts of 6, 7 and 8 . Erosion of Mo was observed on tile 3 in ILW-1, but erosion of $W$ was not observed during ILW-2 on this tile. Outside of areas with deposits the $D$ inventory is generally low. A depletion of $D$ was observed in the near-surface layers (up to a depth of about $10^{18}$ at. $/ \mathrm{cm}^{2}$, about $150 \mathrm{~nm}$ ) of the bulk tungsten tile 5 . This is probably due to isotopic exchange with protium during the last days of the campaign when hydrogen plasmas were performed.

The total amounts of material deposited in the divertor as well as the amount of retained deuterium are comparable in both ILW campaigns. The reduction of the total amount of deposited material as well as of the retained deuterium inventory, as observed in ILW-1, is confirmed in ILW-2 with different and somewhat more powerful plasmas.

\section{Acknowledgements}

This work has been carried out within the framework of the EUROfusion Consortium and has received funding from the Euratom research and training programme 20142018 under grant agreement No 633053. The views and opinions expressed herein do not necessarily reflect those of the European Commission. 
Table 1: Discharge statistics for the first and second JET ITER-like wall campaigns.

\begin{tabular}{|c|c|c|c|c|c|}
\hline $\begin{array}{l}\text { Discharge } \\
\text { campaign }\end{array}$ & $\begin{array}{c}\text { Number of } \\
\text { discharges }\end{array}$ & $\begin{array}{c}\text { Total discharge time } \\
\left(\mathrm{I}_{\mathrm{p}}>0.7 \mathrm{MA}\right) \\
\left(10^{4} \mathrm{~s}\right)\end{array}$ & $\begin{array}{c}\text { Divertor phase } \\
\text { discharge time } \\
\left(10^{4} \mathrm{~s}\right)\end{array}$ & $\begin{array}{c}\text { Limiter phase } \\
\text { discharge time } \\
\left(10^{4} \mathrm{~s}\right)\end{array}$ & $\begin{array}{c}\text { Total input } \\
\text { energy } \\
(\mathrm{GJ})\end{array}$ \\
\hline $2011-2012$ & 3812 & 6.41 & 4.51 & 1.90 & 150.6 \\
\hline $2013-2014$ & 4150 & 7.12 & 5.09 & 2.03 & 200.5 \\
\hline
\end{tabular}


Table 2: Total amounts of elements deposited in the JET divertor during the ILW-2 campaign 20132014.

\begin{tabular}{|l|l|}
\hline Element & $\begin{array}{c}\text { Amount } \\
(\mathbf{g})\end{array}$ \\
\hline $\mathrm{D}$ & 0.82 \\
\hline $\mathrm{Be}$ & 73 \\
\hline $\mathrm{C}$ & 8.2 \\
\hline
\end{tabular}




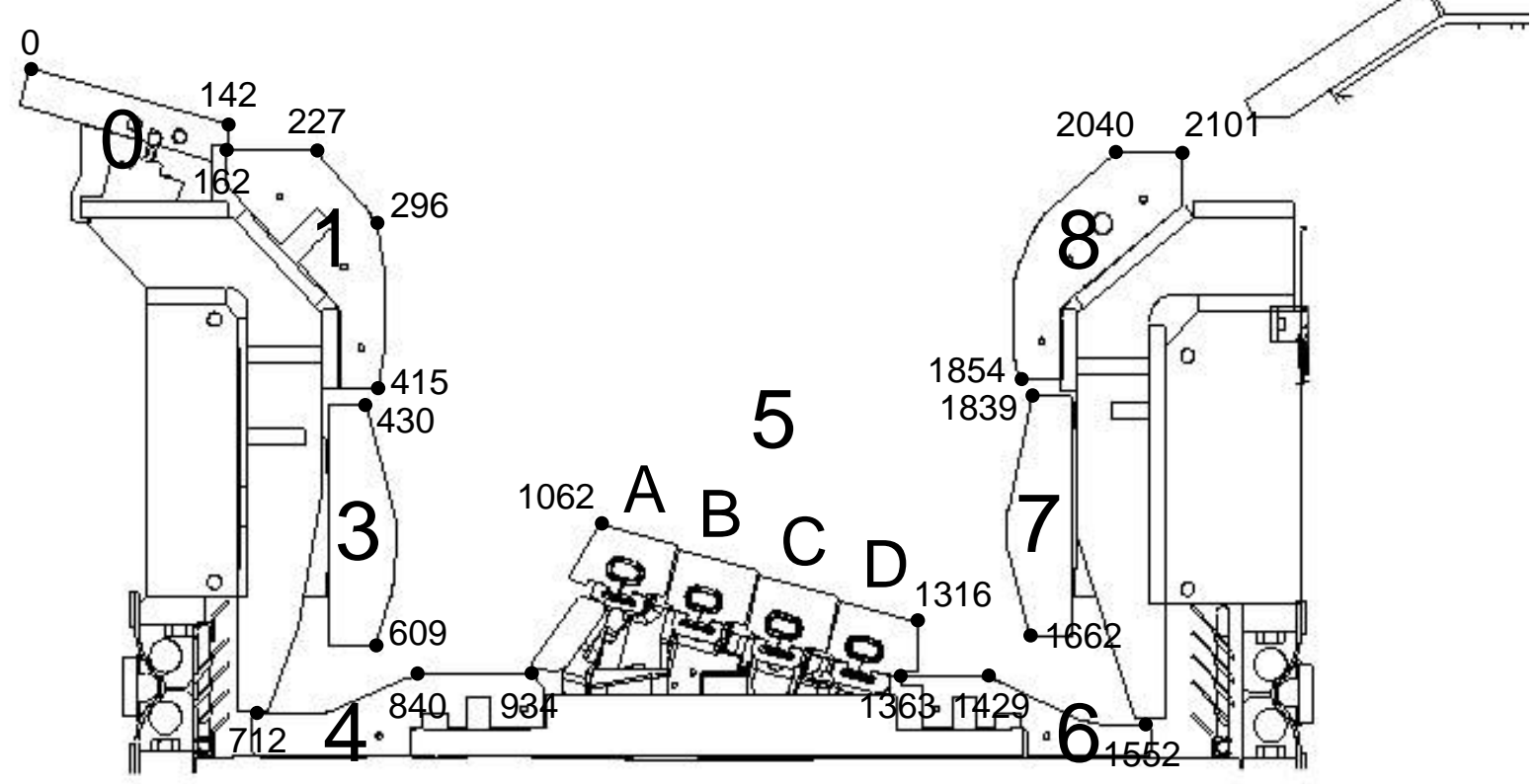

Fig. 1: The JET divertor during the ILW-1 and ILW-2 campaigns. Numbers in large font size are tile numbers. Tile 5 consists of rows of tungsten lamellae ordered in stacks $A-D$, see Fig. 5 for more details. The s-coordinate (in $\mathrm{mm}$ ) is indicated for a few characteristic points in small font size. 


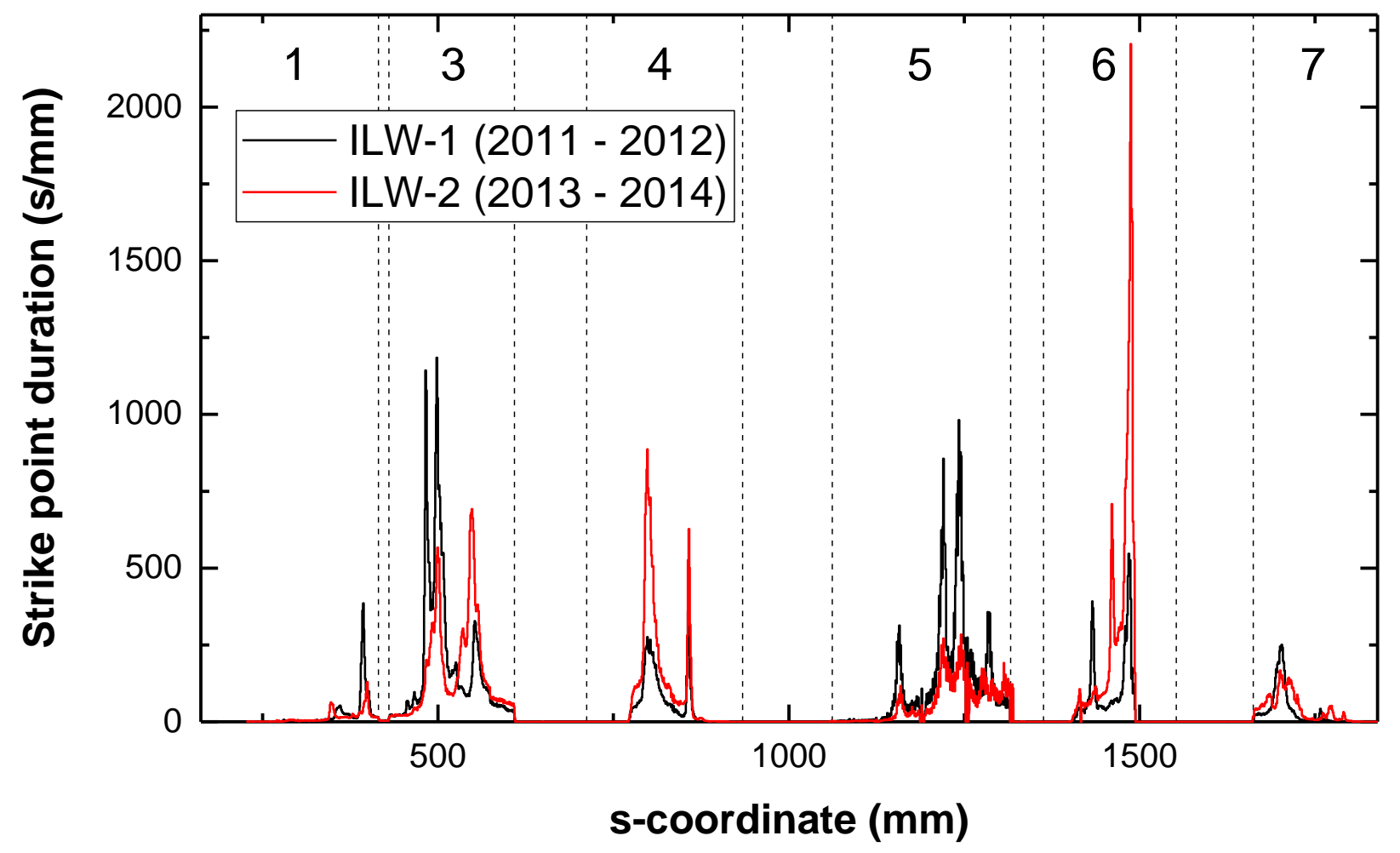

Fig. 2: Plasma strike point distributions for the JET ILW-1 and ILW-2 discharge campaigns. Numbers are divertor tile numbers, see Fig. 1. The strike point was never on tile 0 or tile 8. 


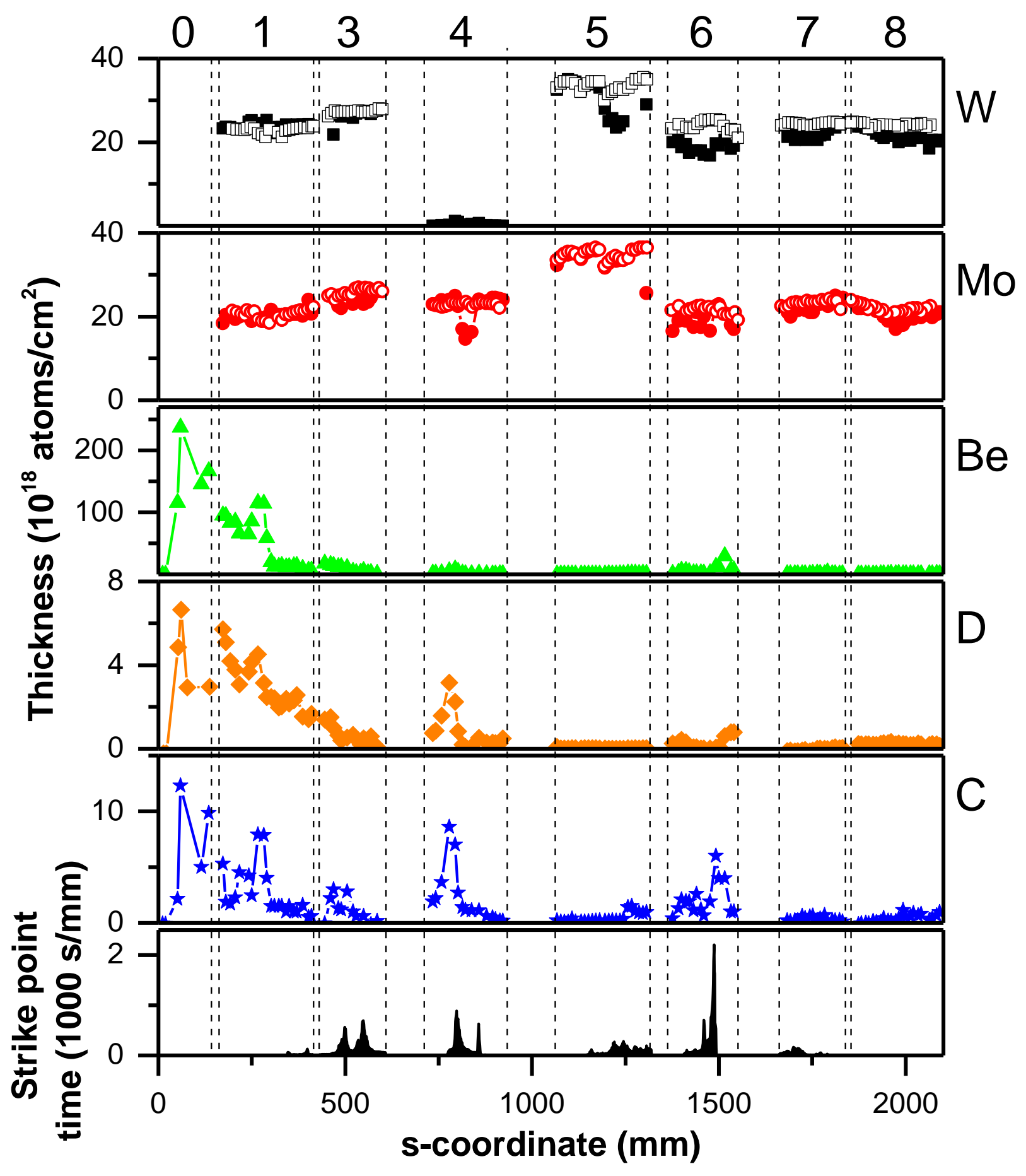

Fig. 3: Thicknesses of the $\mathrm{W}$ and Mo marker layers before and after exposure during the ILW-2 campaign 2013 to 2014 and total deposition of Be, C and D on the marker tiles. Hollow points: Before exposure; Solid points: After exposure. The distribution of strike point positions is shown in the lowest figure. Numbers are divertor tile numbers, see Fig. 1. Massive deposition of $\mathrm{Be}, \mathrm{D}$ and $\mathrm{C}$ is observed on tiles 0 and 1 , some deposition of $\mathrm{C}$ together with $\mathrm{D}$ is also observed on tiles 4 and 6 . Erosion of $W$ is observed on tiles 5 and 6 . 


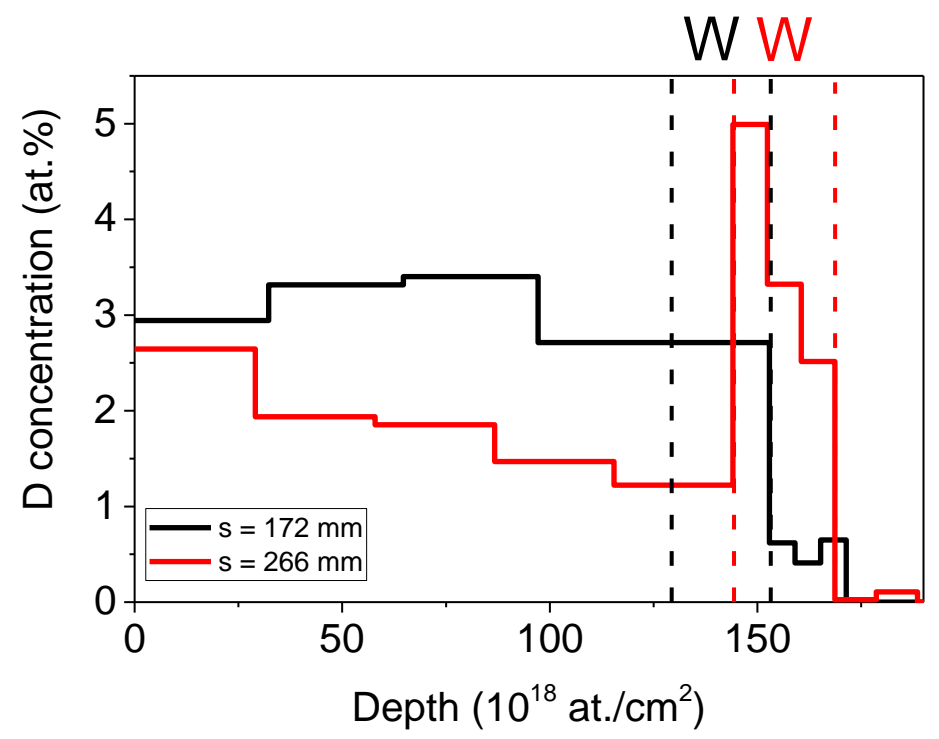

Fig. 4: Deuterium depth profiles from thick deposits on tile 1 for two different s-coordinates. 


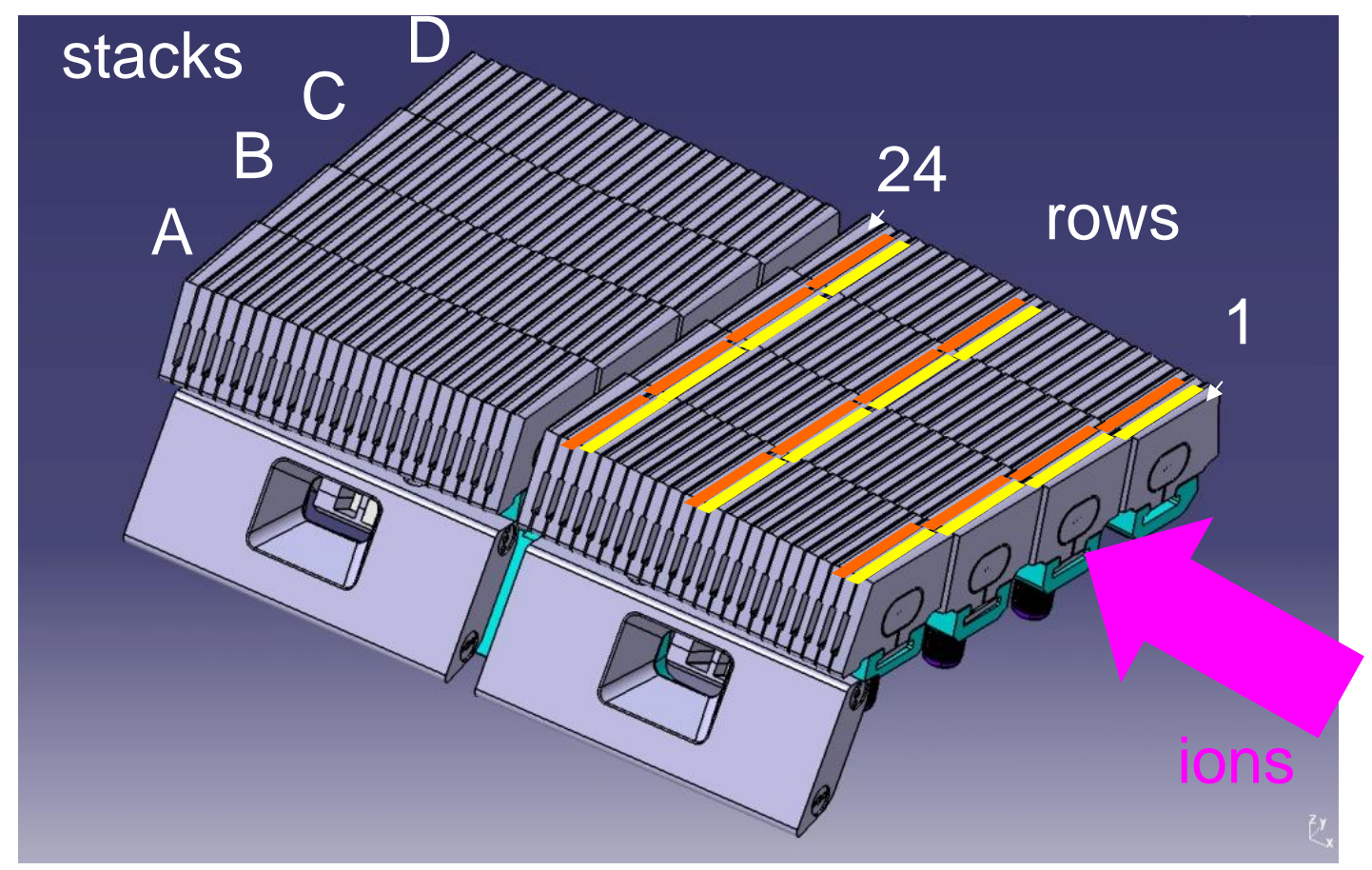

\section{Marker lamellae $\quad$ Bulk W lamellae}

Fig. 5: View of two modules of tile 5. Each module consists of 24 rows of bulk tungsten lamellae in toroidal direction arranged in 4 stacks in poloidal direction; see Fig. 1 for a crosssectional view. Lamellae with markers are marked in yellow, analyzed regular bulk W lamellae are marked in orange. The direction of plasma ions is indicated by the arrow. 


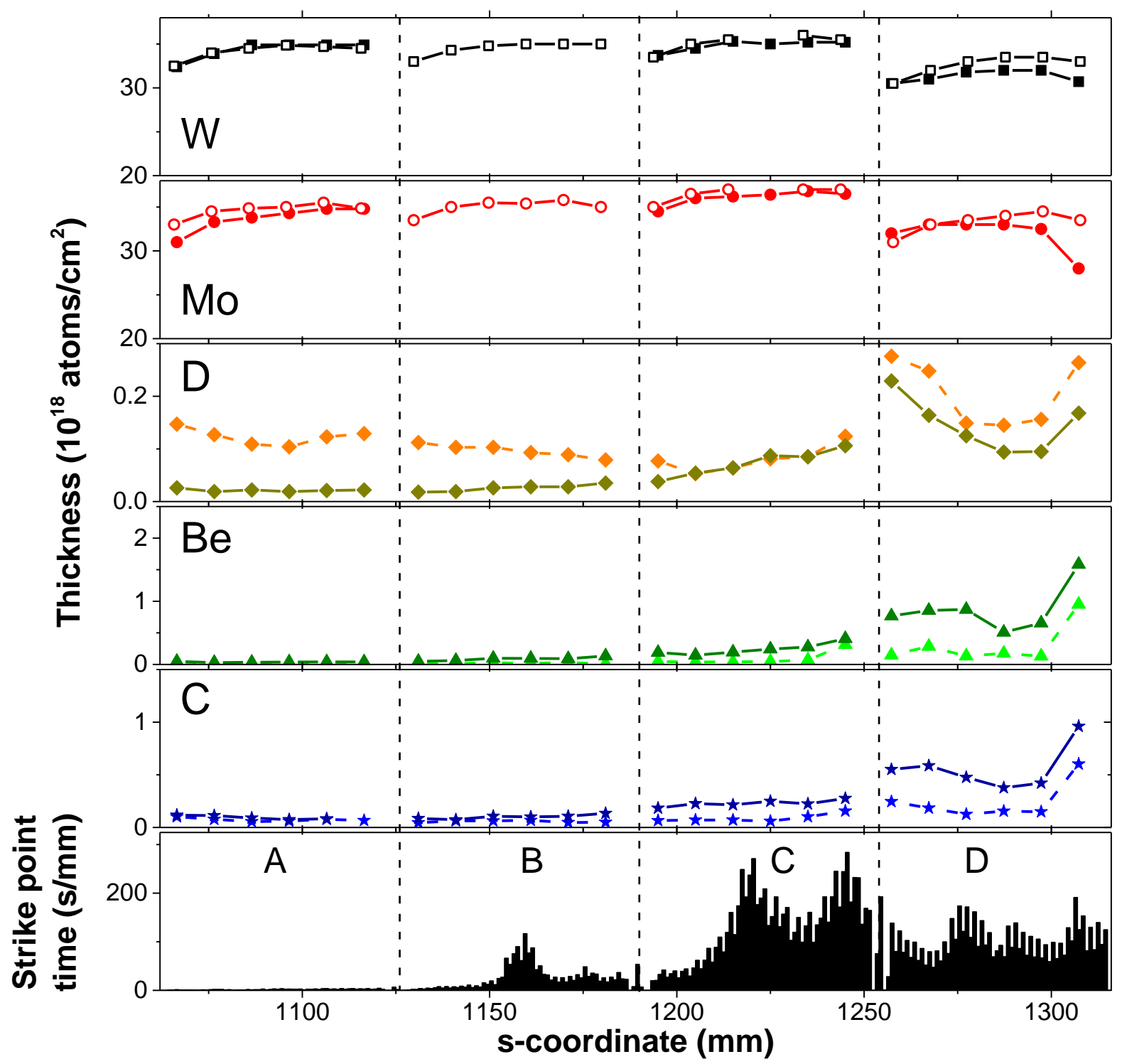

Fig. 6: Thicknesses of the $\mathrm{W}$ and Mo marker layers on lamellae of marker row 2 before and after exposure during the JET-ILW2 campaign 2013 to 2014 and total deposition of $\mathrm{Be}, \mathrm{C}$ and D on the marker lamellae of row 2 and on regular lamellae of row 3. Hollow points: Before exposure; Solid points: After exposure; Dashed lines: Marker lamellae in row 2; Solid lines: Regular lamellae in row 3. The distribution of strike point positions is shown in the lowest figure. See Fig. 1 for the coordinate system and Fig. 5 for lamellae positions. These rows show no erosion of $\mathrm{W}$ and some deposition of $\mathrm{D}, \mathrm{Be}$ and $\mathrm{C}$. 


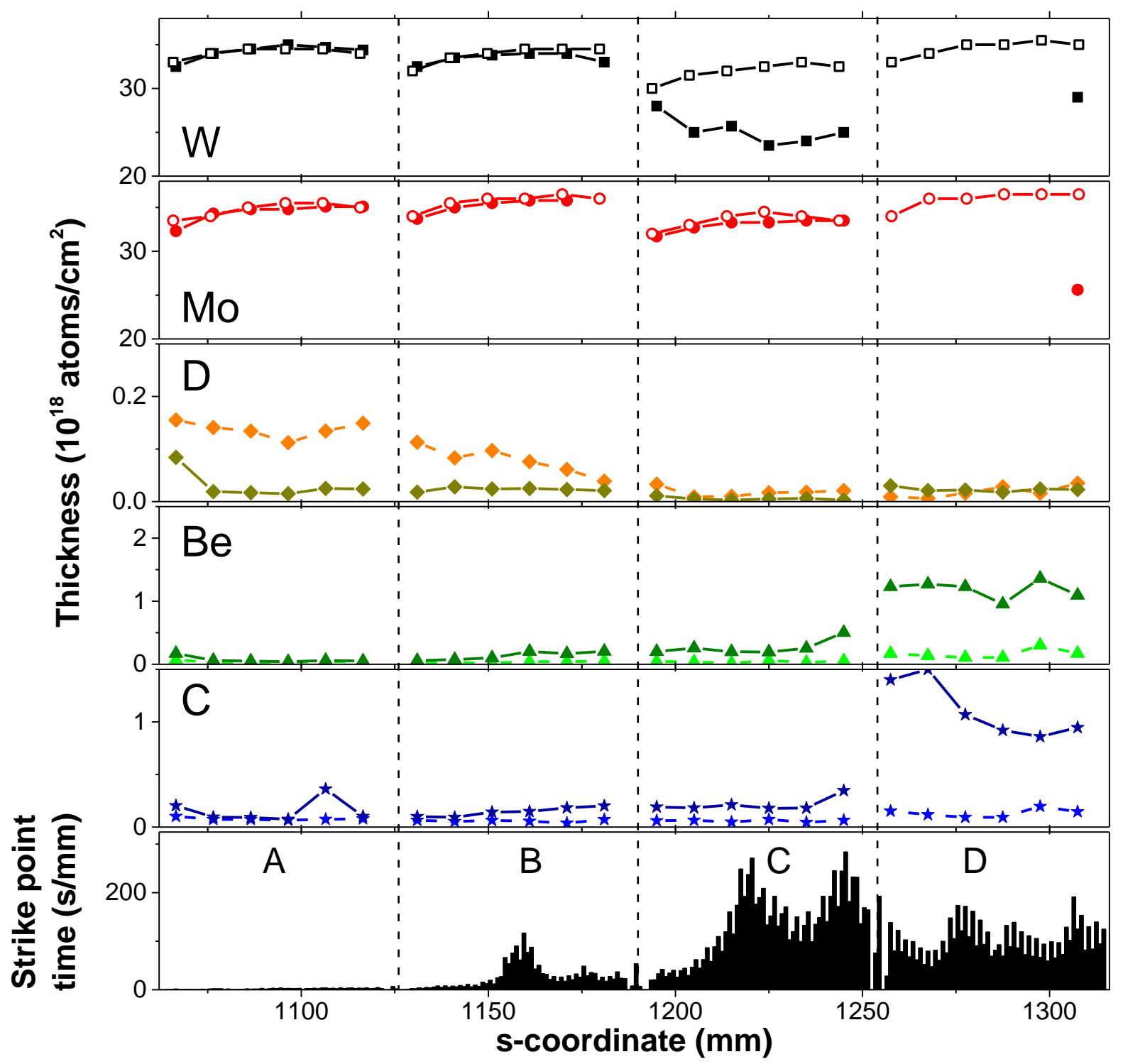

Fig. 7: Thicknesses of the $W$ and Mo marker layers on lamellae of marker row 13 before and after exposure during the JET-ILW2 campaign 2013 to 2014 and total deposition of $\mathrm{Be}, \mathrm{C}$ and D on the marker lamellae of row 13 and on regular lamellae of row 14. Hollow points: Before exposure; Solid points: After exposure; Dashed lines: Marker lamellae in row 13; Solid lines: Regular lamellae in row 14. The distribution of strike point positions is shown in the lowest figure. See Fig. 1 for the coordinate system and Fig. 5 for lamellae positions. The $\mathrm{W}$ marker layer delaminated from stack $D$, so that only very limited information about erosion of $W$ is available from this stack. Erosion of $W$ is observed on stack $C$; some deposition of $D, B e$ and C is observed especially on stacks $A$ and $D$. 


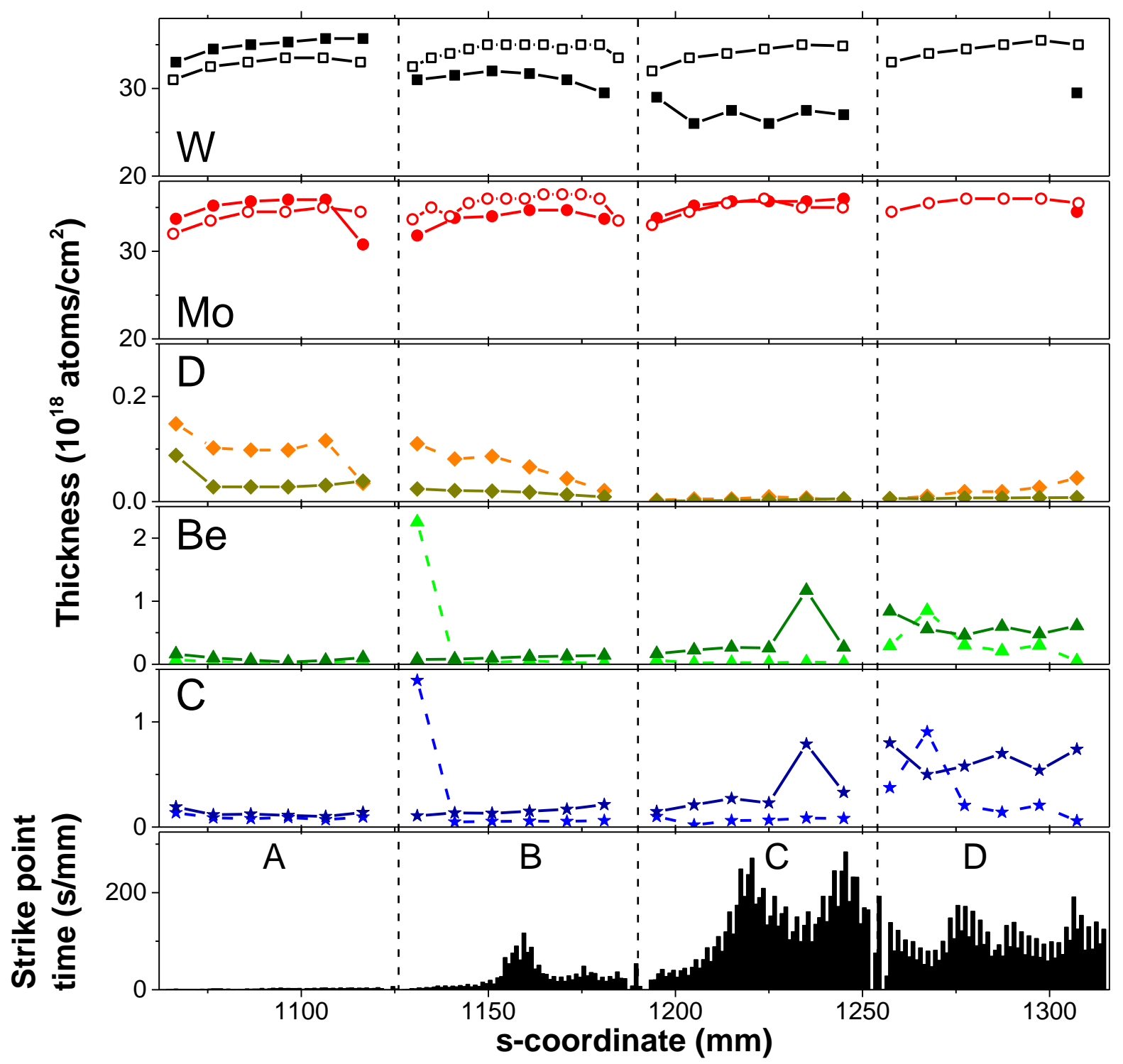

Fig. 8: Thicknesses of the $W$ and Mo marker layers on lamellae of marker row 22 before and after exposure during the JET-ILW2 campaign 2013 to 2014 and total deposition of $\mathrm{Be}, \mathrm{C}$ and D on the marker lamellae of row 22 and on regular lamellae of row 23. Hollow points: Before exposure; Solid points: After exposure; Dashed lines: Marker lamellae in row 22; Solid lines: Regular lamellae in row 23. The distribution of strike point positions is shown in the lowest figure. See Fig. 1 for the coordinate system and Fig. 5 for lamellae positions. The $\mathrm{W}$ marker layer delaminated from stack $D$, so that only very limited information about erosion of $W$ is available from this stack. Erosion of $W$ is observed on stacks $B$ and $C$; some deposition of $D$, $B e$ and $C$ is observed especially on stacks $A$ and $D$. 


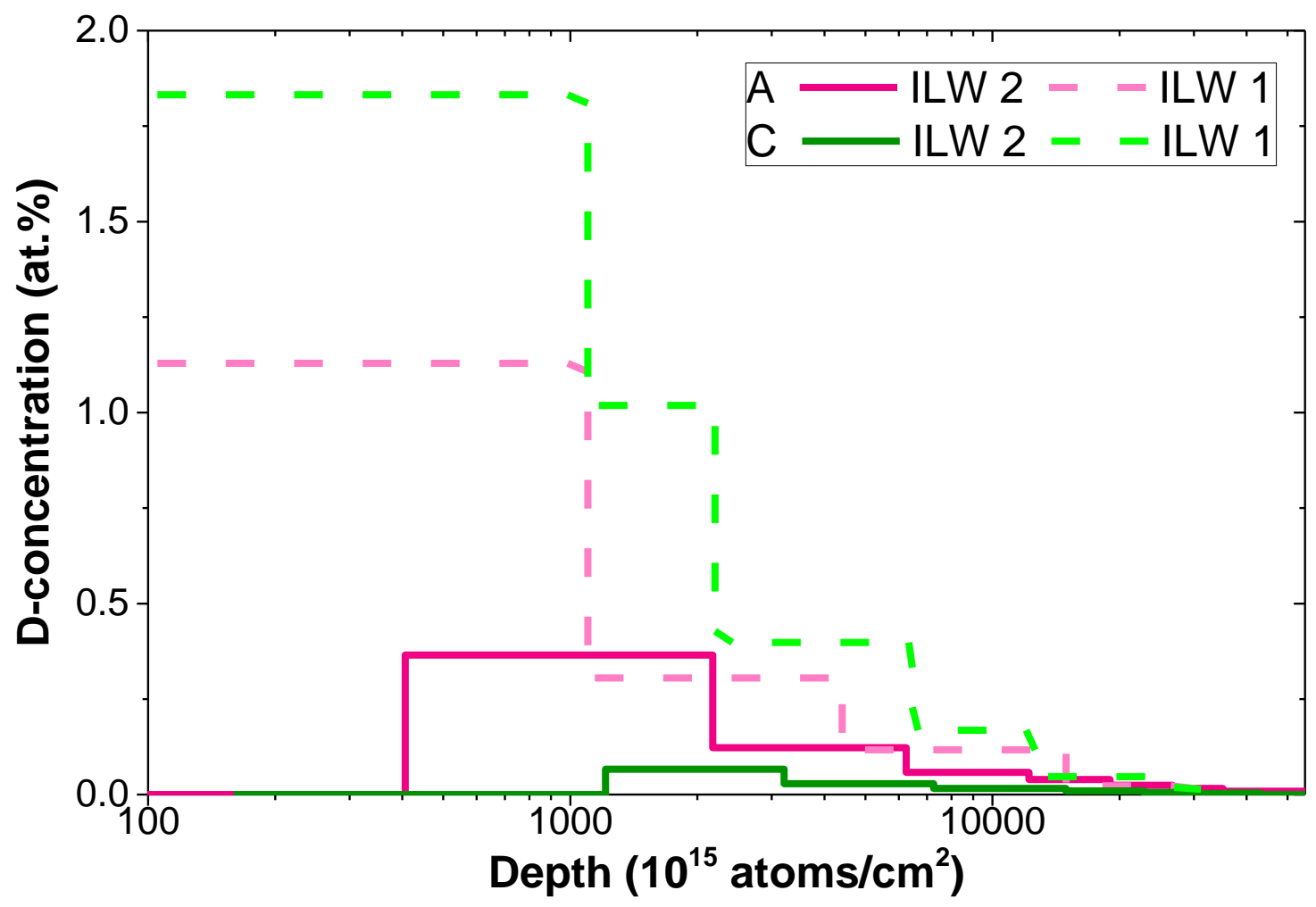

Fig. 9: Deuterium depth profiles from bulk $W$ tile 5 row 14 stacks $A$ and $C$ after the JET ILW-1 and ILW-2 campaigns. After ILW-1 the D depth profiles extended until the tile surfaces, while after ILW-2 the near surface layers were depleted from D.

\footnotetext{
${ }^{1}$ Behrisch R, Mayer M, García-Rosales C 1996 J. Nucl. Mater. 233-237 673

${ }^{2}$ Likonen J et al 2007 J. Nucl. Mater. 363-5 190

${ }^{3}$ Likonen J et al $2015 \mathrm{~J}$. Nucl. Mater. 463842

${ }^{4}$ Krat S et al 2015 J. Nucl. Mater. 463822

${ }^{5}$ Mayer M et al 2016 Phys. Scr. T167 014051

${ }^{6}$ Krat S et al 2015 J. Nucl. Mater. 456106

${ }^{7}$ Mayer M et al 2013 J. Nucl. Mater. 438 S780

${ }^{8}$ Hirai T et al 2015 J. Nucl. Mater. 4631248

${ }^{9}$ Roth J et al 2009 J. Nucl. Mater. 390-391 1

${ }^{10}$ Matthews GF et al 2011 Phys. Scr. T145 14001

${ }^{11}$ Romanelli F 2013 Nuclear Fusion 53104002
} 
${ }^{12}$ Heinola K et al 2016 Phys. Scr. T167 014075

${ }^{13}$ Ruset C et al 2009 Fusion Eng. Des. 841662

${ }^{14}$ Mertens P 2011 Phys. Scr. T 145014002

${ }^{15}$ Rubel M et al 2013 J. Nucl. Mater. 438 S1204

${ }^{16}$ Rubel M et al 2016 Nucl. Instr. and Meth. B 3714

${ }^{17}$ Mayer M et al 2009 Nucl. Instr. and Meth. B 267506

${ }^{18}$ Barradas NP et al 2015 Nucl. Instr. and Meth. B 34621

${ }^{19}$ Lin CS et al 1981 Chinese Journal of Physics (Taiwan) 1999

${ }^{20}$ Mayer M, SIMNRA User's Guide, Tech. rep. IPP 9/113, Garching, Germany MaxPlanck-Institut für Plasmaphysik, 1997

${ }^{21}$ Ziegler JF 2010 Nucl. Instr. and Meth. B 2681818

${ }^{22}$ Mayer M 2002 Nucl. Instr. and Meth. B 194177

${ }^{23}$ Lahtinen A et al 2017 Europhysics Conference Abstracts 41F P2.119 